\title{
Cimetidine prophylaxis for gastrointestinal bleeding in an intensive care unit
}

\author{
A GRoll, J B SIMON, R D WIgle, K TAGUCHI, R J TODD, AND W T DEPEW \\ From the Departments of Medicine and Surgery, Queen's University and Kingston General Hospital, \\ Kingston, Ontario, Canada
}

SUMMARY The efficacy of cimetidine in the prevention of gastrointestinal haemorrhage in a general intensive care unit was evaluated in 221 patients by a placebo controlled double blind randomised study. Criteria for bleeding were (i) haematemesis or gastric aspirate $>50 \mathrm{ml}$ fresh blood, (ii) melaena or fresh blood per rectum with an upper source verified by endoscopy if the gastric aspirate was clear, (iii) a fall in haemoglobin level $>2 \mathrm{~g} / \mathrm{dl}$ in a 24 hour period associated with either $4+$ occult blood in stools, or coffee ground gastric drainage of at least $100 \mathrm{ml}$. The drug and placebo groups were similar for age, sex, duration of study and risk factors. One hundred and fourteen received cimetidine and 107 placebo. Only $8 \%$ of the patients bled with no significant difference between the two groups $(6 / 114$ cimetidine, $11 / 107$ placebo; $p=0 \cdot 16)$. There was no correlation between the frequency of bleeding and either the number of risk factors per patient or the duration of intensive care unit stay. Thirteen patients died in each study group, resulting in overall mortality of $12 \%$. The low incidence of haemorrhage, the lack of statistical benefit from cimetidine and the similar mortality all argue against the routine use of this drug in intensive care unit patients.

Acute gastrointestinal haemorrhage from stress ulceration can be a serious and life threatening complication in critically ill patients. ${ }^{1-4}$ Gastric acid must be present for stress ulcers to occur; ${ }^{56}$ on this basis $\mathrm{H}_{2}$-receptor antagonists such as cimetidine have been tried with the specific aim of reducing the incidence of haemorrhage in these critically ill, high risk patients. A number of prospective controlled studies comparing cimetidine with placebo has produced conflicting results, ${ }^{71}$ and in most only a small number of patients was assessed. We therefore undertoook a large prospective randomised, double blind study to determine whether cimetidine administered prophylactically could lower the incidence of bleeding in a general medical-surgical intensive care unit.

\section{Methods}

PATIENTS

The study was conducted prospectively over a 21

Address for correspondence: Dr A Groll, Division of Gastroenterology, Department of Medicine, Queen's Uiversity, 78 Barrie Street, Kingston, Ontario, Canada K7L 3J7.

Received for publication 7 May 1985 month period in the Kingston General Hospital's medical-surgical intensive care unit. Of a total of 1116 admissions, 378 patients were ineligible because of previously determined exclusions. These included bleeding on admission to the intensive care unit, pregnancy, renal failure requiring haemodialysis or peritoneal dialysis, drug overdosage, acute myocardial infarction, and the use of antacids. Two hundred and seven additional patients were excluded because their stay in the unit was less than 24 hours. Of the remaining 531 eligible patients 221 completed the trial $(41 \%)$. The remainder were excluded because of inability to obtain early consent, refusal to enter the study, death within the first 24 hours, accidental omission by house staff, and miscellaneous reasons (Table 1).

Patients were randomised in a double blind method to receive injections of either cimetidine 300 $\mathrm{mg}$ in $20 \mathrm{ml}$ normal saline or placebo prepared in an identical manner, each given intravenously every six hours. Antacids were not administered to any patient.

The study was terminated when either bleeding occurred or the patient was discharged from the unit. Bleeding was defined by the following strin- 
Table 1 Intensive care unit admissions

\begin{tabular}{llc}
\hline $\begin{array}{l}\text { Total intensive care unit admissions } \\
\text { Ineligible re protocol }\end{array}$ & 378 & 1116 \\
$\quad$ Discharged within 24 hours & 207 & \\
Eligible for trial & & 531 \\
Exclusions & & \\
$\quad$ Refusal to enter study & 83 & \\
$\quad$ Early consent unobtainable & 69 & \\
Overlooked by housestaff & 86 & \\
$\quad$ Death <24 hours & 48 & \\
$\quad$ Miscellaneous & 24 & \\
Completed trial & & 221 \\
\hline
\end{tabular}

gent criteria: (i) frank haematemesis or gastric aspirate of $>50 \mathrm{ml}$ fresh blood, (ii) melaena or fresh blood per rectum with an upper source of haemorrhage verified by endoscopy if the gastric aspirate was clear, (iii) a fall in haemoglobin level $>2 \mathrm{~g} / \mathrm{dl}$ in a 24 hour period associated with either $4+$ occult blood in the stools or coffee ground gastric drainage of at least $100 \mathrm{ml}$. Upper gastrointestinal endoscopy was not a prerequisite for entry into the study as its routine use was considered unwarranted in critically ill patients.

A clinical research assistant was attached to the intensive care unit to monitor the entry and course of the patients. Statistical evaluation of the data was done by $\chi^{2}$ analysis. Informed consent was obtained from either the patient or his closest relative as well as from the patient's personal physician. The study was approved by the committee on human research, Department of Medicine, Queen's University.

\section{Results}

Two hundred and twenty one patients completed the trial, 114 in the cimetidine and 107 in the placebo group. Table 2 describes the characteristics of the patient population.

Only $8 \%$ of the patients bled. This comprised six patients in the cimetidine group (5\%) and 11 in the placebo group $(10 \%)$. Although fewer bleeds on cimetidine did occur, the difference was not statistically significant $(p=0 \cdot 16)$. Thirteen patients died in

Table 2 Patient population

\begin{tabular}{lcl}
\hline & Placebo & Cimetidine \\
\hline Patients (no) & 107 & 114 \\
Male/female ratio & $68 / 39$ & $75 / 39$ \\
Mean age (range) & $57(15-88)$ & $58(16-90)$ \\
Mean days in trial (range) & $3 \cdot 6(1-20)$ & $3 \cdot 8(1-23)$ \\
Bleeds (no) & $11(10 \%)$ & $6(5 \%)$ \\
Deaths during study & $13(12 \%)$ & $13(11 \%)$ \\
\hline
\end{tabular}

each group, resulting in an overall mortality of $12 \%$. None of the deaths in either group was directly due to bleeding. The duration of bleeding in the cimetidine group ranged from one to six days with a mean of 3.0 days and in the placebo group from one to nine days with a mean of 2.9 days. The bleeding was only mild in most cases. The volume of packed cells administered to the cimetidine group ranged from 0 to $900 \mathrm{ml}$ with a mean of $600 \mathrm{ml}$ and in the placebo group from 0 to $1200 \mathrm{ml}$ with a mean of 550 $\mathrm{ml}$. Bleeding did not lead to haemodynamic instability in any of the patients and was not a contributing factor to the death of the one patient who died in the cimetidine group or of the three who died in the placebo group.

Eight major risk factors were analysed for each patient: major operative procedure, respiratory failure, sepsis, shock, trauma, coma, renal failure and jaundice. The percentage of patients with each risk factor is shown in Figure 1. With the exception of sepsis, there was a close similarity between the two groups. Cumulative risk factors for each individual were analysed; Figure 2 shows the number of patients in each group with one, two, and three-six risk factors. The mean number of risk factors was two per patient in both study groups. There was no correlation between the occurrence of haemorrhage and the number of risk factors in either the cimetidine or the placebo groups. Tables 3 and 4 tabulate the primary diagnosis and the associated risk factors for each patient who bled.

The relationship between the occurrence of haemorrhage and the duration of study was analysed for each group (Figure 3). Seventy per cent of patients were in the study for 1-3 days, and during

\section{Table 3 Bleeding in placebo group}

\begin{tabular}{|c|c|}
\hline Primary diagnosis & Risk factors \\
\hline Aortic aneurysm & Major operative procedure \\
\hline Aortic aneurysm & Major operative procedure \\
\hline Aortic aneurysm & $\begin{array}{l}\text { Major operative procedure, } \\
\text { shock }\end{array}$ \\
\hline Peripheral vascular disease & Major operative procedure \\
\hline Gunshot wound & $\begin{array}{l}\text { Coma, trauma, respiratory } \\
\text { failure, shock, sepsis, major } \\
\text { operative procedure }\end{array}$ \\
\hline Staphylococcal pneumonia & $\begin{array}{l}\text { Septic shock, respiratory } \\
\text { failure }\end{array}$ \\
\hline COPD and pneumonia & $\begin{array}{l}\text { Respiratory failure, sepsis, } \\
\text { shock }\end{array}$ \\
\hline Right hemisphere CVA & Coma, liver failure \\
\hline Subarachnoid haemorrhage & $\begin{array}{l}\text { Coma, major operative } \\
\text { procedure }\end{array}$ \\
\hline Brain stem haemorrhage & $\begin{array}{l}\text { Coma, respiratory failure, } \\
\text { major operative procedure }\end{array}$ \\
\hline Recurrent carcinoma cervix & Major operative procedure \\
\hline
\end{tabular}




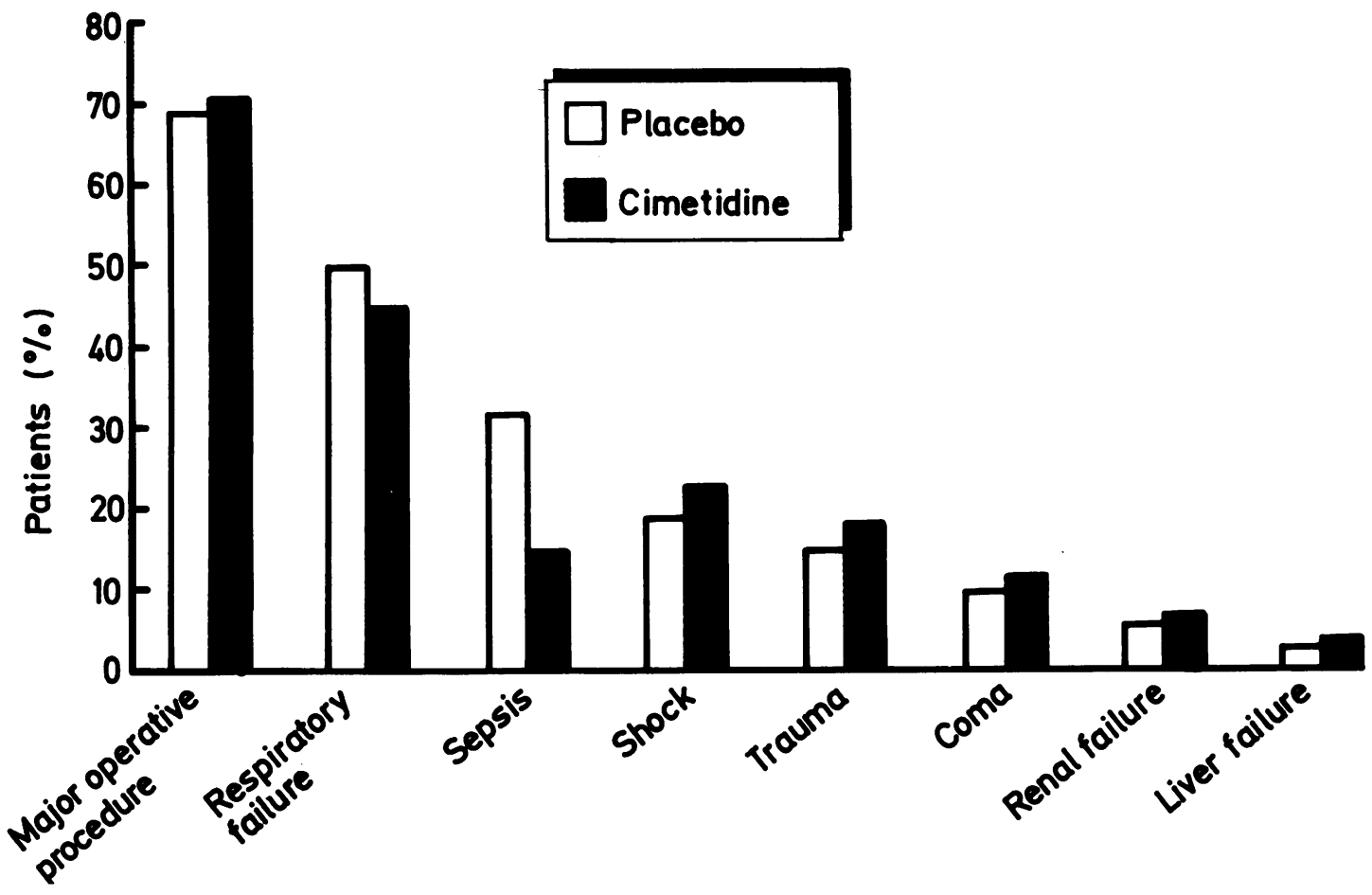

Fig. 1 Distribution of patients according to risk factors.

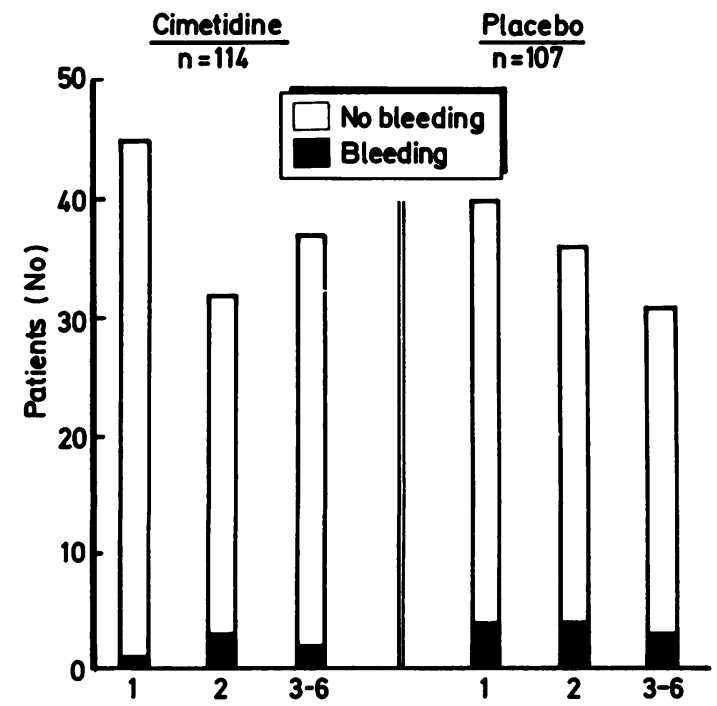

Fig. 2 Distribution of patients according to number of risk factors and incidence of bleeding. this time nine of the 11 placebo and five of the six cimetidine patients started to bleed (NS).

\section{Discussion}

In this study prophylactic cimetidine therapy did not significantly decrease the risk of acute gastrointestinal haemorrhage in critically ill patients. The drug and placebo groups were similar for age, sex, duration of study and risk factors. The number of patients with each risk factor known to predispose to

Table 4 Gastrointestinal bleeding in cimetidine group

\begin{tabular}{|c|c|}
\hline Primary diagnosis & Risk factors \\
\hline MVA - multiple injuries & $\begin{array}{l}\text { Trauma, respiratory failure, } \\
\text { shock, major operative } \\
\text { procedure }\end{array}$ \\
\hline Intracerebral haemorrhage & $\begin{array}{l}\text { Coma, respiratory failure, } \\
\text { major operative failure }\end{array}$ \\
\hline $\begin{array}{l}\text { Peripheral vascular disease } \\
\text { Aortic aneurysm }\end{array}$ & $\begin{array}{l}\text { Major operative procedure } \\
\text { Major operative procedure, } \\
\text { respiratory failure }\end{array}$ \\
\hline Carcinoma duodenum & $\begin{array}{l}\text { Major operative procedure, } \\
\text { jaundice }\end{array}$ \\
\hline Spontaneous rupture spleen & $\begin{array}{l}\text { Major operative procedure, } \\
\text { shock }\end{array}$ \\
\hline
\end{tabular}




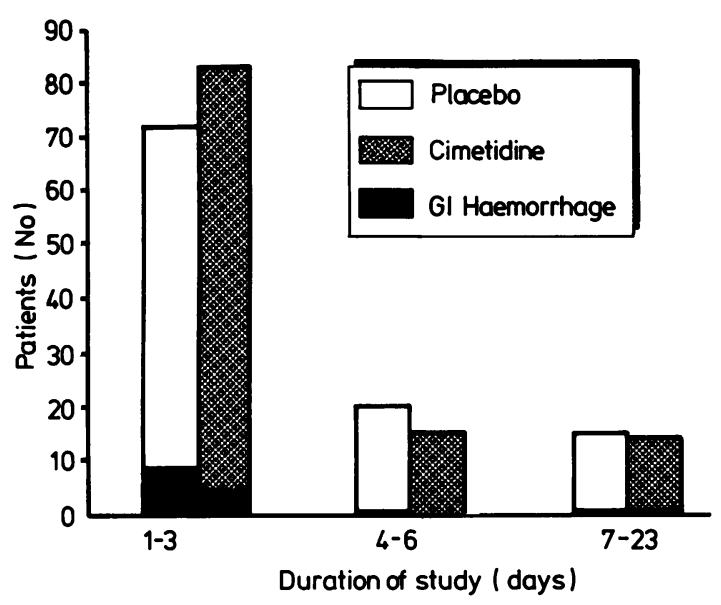

Fig. 3 Duration of study and incidence of bleeding in cimetidine and placebo groups.

stress ulceration and the mean number of risk factors per patient were similar in both groups. Although the total number of risk factors indicated that these patients were indeed critically ill, bleeding was uncommon. The almost identical mortality rates further indicate that severely ill patients were appropriately distributed between the cimetidine and placebo groups.

Though the difference in bleeding rates was not statistically significant, fewer bleeds did occur in the cimetidine group. A larger study may therefore have shown the drug to be efficacious. If the bleeding rates observed in the current study were to be applied to an expanded population, however, it can be shown that 600 patients would be required in each group to have an acceptable probability $(\beta=0 \cdot 10)$ of finding a significant difference $(\alpha=0.5)$ if true bleeding rates were those observed in the sample. ${ }^{12}$ Even if the study achieved significance under these particular circumstances, the use of the drug in preventing haemorrhage may not be clinically justified because only $5 \%$ of the patients treated with cimetidine appear to have derived benefit.

The incidence of bleeding in the control group was $10 \%$, somewhat lower than the mean rate (20\%) found in comparable prospective double blind studies. $^{7101314}$ Our figure compares favourably with the $14 \%$ incidence found by Basso ${ }^{10}$ and in a recent prospective evaluation by Schuster et al. ${ }^{15}$ The reasons for the lower incidence remain unclear. It cannot be ascribed to a difference in the severity of illness in the drug and placebo groups as the number of patients with each risk factor was similar in each group. Moreover the severity of illness in our study based on the distribution of risk factors is comparable with other studies. ${ }^{310} 14$ Use of antacids was not responsible for the low incidence as none of our patients received antacids. Possibly our strict criteria for defining haemorrhage may have contributed to the lower bleeding rate.

Our results may not necessarily apply to critically ill patients in other intensive care unit settings. For example, burn patients ${ }^{116}$ who have a high incidence of stress ulceration are not nursed in our general medical-surgical intensive care unit. It could also be argued that the number of excluded patients may have influenced the outcome. Only $20 \%$ of all patients admitted to the unit were entered into the study. The number of excluded patients reflects the difficulties encountered in establishing clinical protocols in critically ill patients. Many patients did not meet the study criteria, or had already been started on antacids or cimetidine before admission to the intensive care unit. For some permission for entry into the study was denied and several patients were not randomised on admission to the intensive care unit. Nevertheless our figures compare very favourably with other intensive care unit studies ${ }^{310}{ }^{14}$ with regard to the number of patients entering the study as well as to the distribution of risk factors. As a formal demographic comparison of excluded and included patients was not done, our conclusions cannot be extended to the excluded patients whose characteristics may have differed from those of the study group.

In contrast with previous studies, ${ }^{13}{ }^{14}$ we found no correlation between the number of risk factors per patient and the risk of bleeding - bleeding occurred equally frequently in the presence of one, two, or more risk factors. Neither did the duration of intensive care unit stay correlate with the frequency of bleeding, as the large majority of haemorrhages occurred during the first 72 hours. This observation suggests that bleeding would not have been much more common had we studied a larger group of patients whose stay was longer than 72 hours.

This is the largest prospective double blind study comparing cimetidine with placebo for the prevention of gastrointestinal haemorrhage in an intensive care unit population. Most other prospective studies have compared cimetidine with antacids and some did not include a placebo group. There are three clinical trials showing the superiority of cimetidine over placebo. Basso and coworkers ${ }^{10}$ studied 168 of 800 intensive care unit patients in a single blind fashion and found cimetidine to be superior to placebo, but not to antacids, in the prevention of bleeding. In a double blind study of 50 patients with severe head injuries Halloran ${ }^{11}$ also found cimetidine superior to placebo in the prevention of 
bleeding. In another controlled trial cimetidine was significantly superior to placebo in 50 patients with fulminant hepatitis. ${ }^{8}$ In contrast, however, Zinner and coworkers ${ }^{7}$ could find no difference between cimetidine and placebo, whereas antacids appeared to be efficacious in the prevention of haemorrhage. Friedman and coworkers ${ }^{9}$ studied 36 of 150 patients requiring mechanical ventilation and could show no significant difference between cimetidine and placebo, while in a large study comparing antacids with cimetidine Priebe and coworkers ${ }^{14}$ established antacids to be superior to cimetidine in the prevention of haemorrhage; neither treatment was compared with placebo. In another study by the same investigators, ${ }^{13}$ antacids were found to be superior to a control group who received no specific form of treatment. The incidence of bleeding $(25 \%)$ was the same in the cimetidine treated patients (versus antacids) and in the control group (versus antacids). These findings suggest that cimetidine may be no better than placebo in the prevention of haemorrhage in that particular intensive care unit population.

The objective of our study was to determine the efficacy of cimetidine in preventing haemorrhage, not to establish the incidence of stress ulceration which commonly occurs in intensive care unit populations. We therefore deliberately did not routinely include an endoscopic evaluation but reserved it for those patients in whom bleeding warranted such investigation. The low incidence of haemorrhage in this study suggests either that stress ulceration is uncommon in such a setting or that only a small proportion of patients with ulceration bleed. Other studies suggest that the latter is much more likely than the former. ${ }^{1516}$ In either case the outcome of our study suggests that cimetidine should not be prescribed prophylactically to all patients entering a general medical-surgical intensive care unit. The low incidence and mild extent of the haemorrhage, the lack of statistical benefit from cimetidine and the similar mortality in the two study groups all argue against the routine use of this agent. In other studies, ${ }^{13} 141718$ however, the incidence of haemorrhage in critically ill patients has been significantly reduced by the hourly antacid titration of gastric juice to a $\mathrm{pH}$ greater than 3.5. Thus antacids may be superior to cimetidine as prophylaxis against bleeding from stress ulceration.

We are indebted to Ruth Pattenden for supervising the study and to the physicians and nurses of the Kingston General Hospital Intensive Care Unit for their cooperation and support. This project was supported by Smith Kline and French Canada Ltd.

\section{References}

1 Czala AG, McAlhany MC, Pruitt BA. Acute gastroduodenal disease after thermal injury. $N$ Engl $J$ Med 1974; 291: 925-9.

2 Skillman JJ, Silen W. Stress ulceration in the acutely ill. Ann Rev Med 1976; 27: 9-22.

3 Lucas CE, Sugawa C, Riddle J, Rector F, Rosenberg B, Walt AJ. Natural history and surgical dilemma of 'stress' gastric bleeding. Arch Surg 1971; 102: 266-73.

4 Skillman JJ, Bushnell LS, Goldman H, Silen W. Respiratory failure, hypotension, sepsis and jaundice, a clinical syndrome associated with lethal haemorrhage from acute stress ulceration of the stomach. Am J Surg 1969; 117: 523-30.

5 Moody FG, Aldrete JS. Hydrogen permeability of canine gastric secretory epithelium during formation of superficial erosions. Surgery 1971; 70: 154-60.

6 Menguy R, Desbaillets L, Masters YF. Mechanism of stress ulcers: influence of hypovolemic shock on energy metabolism in the gastric mucosa. Gastroenterology 1974; 66: 46-56.

7 Zinner MJ, Zuidema GD, Smith PL, Mignosa M. The prevention of upper gastrointestinal tract bleeding in patients in an intensive carc unit. Surg Obst Gynecol 1981; 153: 214-20.

8 MacDougall BRD, Bailey RJ, Willıams R. $\mathrm{H}^{2}$-receptor antagonists and antacids in the prevention of acute gastrointestinal haemorrhage in fulminant hepatic failure. Lancet 1977; 1: 617-9.

9 Friedman CJ, Oblinger MJ, Suratt PM et al. Prophylaxis of upper gastrointestinal haemorrhage in patients requiring mechanical ventilation. Crit Care Med 1982; 10: $316-9$.

10 Basso N, Bagarani M, Materia A, Fiorani S, Lunardi P, Speranzo V. Cimetidine and antacid prophylaxis of acute upper gastrointestinal bleeding in high risk patients. Am J Surg 1981; 141: 339-41.

11 Halloran LG, Zfass AM, Gayle WE, Wheeler CB, Miller JD. Prevention of acute gastrointestinal complications after severe head injury. A controlled trial of cimetidine prophylaxis. Am J Surg 1980; 139: 44-8.

12 Colton $\mathrm{T}$. Inference on proportions. In: Colton T, ed. Statistics in medicine. Boston: Little Brown 1974: 168-9.

13 Hastings PR, Skillman JJ, Bushnell LS, Silen W. Antacid titration in the prevention of acute gastrointestinal bleeding. A controlled randomised trial in 100 critically ill patients. $N$ Engl J Med 1978; 298: 1041-5.

14 Priebe HJ, Skillman JS, Bushnell LS, Long PC, Silen W. Antacid versus cimetidine in preventing acute gastrointestinal bleeding. $N$ Engl Med 1980; 302: 426-30.

15 Schuster DP, Rowley H, Feinstein S, McGue MK, Zuckerman GR. Prospective evaluation of the risk of upper gastrointestinal bleeding after admission to a medical intensive care unit. Am J Med 1984; 76: 623-30.

16 McElwee HP, Sikilnek KR, Levine BA. Cimetidine affords protection equal to antacids in the prevention of stress ulceration following thermal injury. Surgery 
1979; 86: 620-6.

17 McAlhany JC Jr, Czaja AJ, Pruitt BA Jr. Antacid control of complications from acute gastroduodenal disease after burns. J Trauma 1976; 16: 645-8.
18 Skillman JJ, Lisbon A, Long PC, Silen W. 15 (R)-15 methyl prostaglandin does not prevent gastrointestinal bleeding in seriously ill patients. Am J Surg 1984; 147: 451-5. 